\title{
Verlaufsbeobachtung des fernmetastasierten Melanoms mit der Laktatdehydrogenase und dem C-reaktiven Protein
}

\author{
M. Deichmann
}

\author{
Study of the Course of Melanoma with Distant Metastases Using Lactate \\ Dehydrogenase and C-Reactive Protein
}

\section{Zusammenfassung}

Zur Evaluierung von serologischen Verlaufsparametern der fernmetastasierten Melanom-Erkrankung wurden drei prospektive Studien durchgeführt. Die Ergebnisse der Staging-Untersuchungen wurden als unabhängiger Referenz-Standard zur Diagnose einer Erkrankungs-Progredienz verwandt, und Interleukin-6 (Il-6), sein Surrogat C-reaktives Protein (CRP) und der konventionelle Parameter Laktatdehydrogenase (LDH) wurden zum Zeitpunkt der Staging-Untersuchungen im Serum bestimmt. Zum Vergleich wurden die Melanom-Marker S100ß und „melanoma inhibitory activity“ (MIA) in den Seren gemessen. Die Patienten mit Progredienz der Metastasierung wiesen statistisch signifikant höhere Konzentrationen der Serumparameter als die Patienten mit Therapieansprechen auf, wenn beide Gruppen durch Medianwerte verglichen wurden. Mit der Fläche unter den „Receiver Operating Characteristic“ (ROC)-Kurven zeigten sich sowohl Il-6, sein Surrogat CRP und die LDH als auch S100 $\beta$ und MIA geeignet, eine Progression der Metastasierung tendenziell zu erkennen. In der multiplen logistischen Regressions-Analyse resultierte die LDH als relevanter Faktor. Aufgrund ihrer hohen Korrelationen mit der LDH konnten S100ß und MIA die Information der LDH nur geringfügig verbessern. Unter Anwendung von „classification and regression trees“ (CART) erwies sich das CRP mit einem Grenzwert von $0,5 \mathrm{mg} / \mathrm{dl}$ als der am meisten relevante Parameter.

\section{Abstract}

Monitoring melanoma patients suffering from distant metastases (American Joint Committee on Cancer stage IV), we evaluated serum markers for the ability to discriminate progressive from non-progressive disease. In three prospective studies, results of staging examinations were used as independent reference standard for diagnosing progressive disease, and interleukin-6 (Il-6), its surrogate C-reactive protein (CRP) and the conventional parameter lactate dehydrogenase (LDH) were determined in serum just before. For comparison, the melanoma markers $S 100 \beta$ and melanoma inhibitory activity (MIA) were measured in the sera. We found all tested serum parameters to be significantly elevated in progressive disease by median values. Calculating the areas under the Receiver Operating Characteristic (ROC) curves, Il-6, its surrogate CRP and LDH as well as S100 $\beta$ and MIA were useful in diagnosing progressive disease. By multiple logistic regression analysis, $\mathrm{LDH}$ resulted as relevant factor. $\mathrm{S} 100 \beta$ and MIA did not provide additional significant information as they highly correlated with $\mathrm{LDH}$ with respect to clinical outcome. Applying classification and regression trees (CART), we found CRP with a cut off value of $0.5 \mathrm{mg} / \mathrm{dl}$ to be the most relevant serum marker.

\section{Einleitung}

Für Patienten mit fernmetastasiertem Melanom wäre ein Tumormarker im Serum wünschenswert, mit dem der Verlauf der Erkrankung bzw. Ansprechen oder Versagen von Immunchemo- therapien bewertet werden könnte. Ein solcher Parameter könnte Interleukin-6 (Il-6) sein, da erhöhte Serumwerte dieses Zytokins bei Patienten mit metastasiertem Melanom mit Versagen von Immunchemotherapien und mit kürzeren medianen Überlebenszeiten assoziiert waren [1 - 3]. Il-6 gilt als Wachstumsfaktor 
beim Melanom: Melanom-Zellen exprimieren Il-6-Rezeptoren auf der Zellmembran, und Il-6 stimuliert Melanom-Zellen in der Proliferation [4-6]. Da in humanen Melanom-Zelllinien Il-6 auf mRNA-Ebene [6-9] und auf Protein-Ebene [10] nachgewiesen werden konnte, ist eine autokrine Stimulation des MelanomWachstums durch dieses Zytokin wahrscheinlich.

Wir untersuchten daher in einer ersten prospektiven Studie Serumwerte von Il-6 auf ihren Wert, eine aktuelle Progression der Melanom-Metastasierung unter Therapie anzuzeigen. Da die Synthese von C-reaktivem Protein (CRP) in Leberzellen durch Il-6 induziert wird und die Höhe der CRP-Werte im Serum die Il6-Aktivität in vivo reflektiert [11,12], wäre möglicherweise auch die Messung dieses Akut Phase-Proteins für die Verlaufsbeobachtung des fortgeschrittenen Melanoms unter Therapie nützlich. Die Ergebnisse von Il-6 und CRP verglichen wir mit der konventionellen Laktatdehydrogenase (LDH), die bereits früher als die beste prognostische Variable bezüglich des Überlebens des metastasierten Melanoms beschrieben wurde [13 - 15].

In einer zweiten prospektiven Studie untersuchten wir, ob mit der LDH ein aktuelles Fortschreiten der Melanom-Metastasierung genauso gut erkannt werden kann wie mit den aktuell favorisierten Melanom-Markern $S 100 \beta$ und „melanoma inhibitory activity“ (MIA). In einer dritten Studie überprüften wir, ob Verlaufsmessungen von S100 $\beta$, MIA und CRP während der Therapie aussagekräftiger als Einfachmessungen zum Zeitpunkt des ReStagings sind.

\section{Patienten und Methoden}

\section{Patienten}

In drei prospektiven Studien wurden von April 1997 bis November 1999 konsekutiv 74, 71 bzw. 67 Patienten mit fernmetastasiertem Melanom eingeschlossen. Bei allen Patienten war die Melanom-Diagnose histologisch bestätigt, und alle Patienten waren klinisch dem Stadium IV nach den Kriterien des „American Joint Committee on Cancer" (AJCC) [16] zugeordnet.

Die Zeitspanne zwischen Therapie und Re-Staging, d.h. der klinischen und apparativen Re-Evaluierung der Metastasenausbreitung, betrug mindestens drei Wochen. Serumproben wurden direkt vor der Evaluierung der Metastasierung beim Re-Staging gewonnen, bei dem Progression von Nicht-Progression der Erkrankung unterschieden wurden. Der Verlauf der Erkrankung und ein Ansprechen auf die Therapie wurden durch klinische Untersuchungen, Routine-Labor, Röntgen-, Ultraschall-Untersuchungen, Computertomographie und Kernspintomographie bewertet. Komplettes, partielles und gemischtes Ansprechen, stabile Erkrankung und die fehlende Nachweisbarkeit von Metastasierung („no evidence of disease“, NED) wurden als nicht-progrediente Erkrankung zusammengefasst.

\section{Messungen von CRP, LDH, II-6, S100 $\beta$ und MIA}

CRP und LDH wurden im Zentrallabor des Universitätsklinikums mit Routine-Methoden gemessen: Die LDH-Werte wurden auf einem Beckmann-LX20-Gerät bestimmt (Beckmann-Instru- ments, Gagny, Frankreich), und CRP in den Serumproben wurde immunonephelometrisch auf einem BN2-Gerät (Dode-Behring, München) quantifiziert. Die oberen Grenzwerte für LDH und CRP lagen bei $240 \mathrm{U} / \mathrm{ml}$ bzw. $0,5 \mathrm{mg} / \mathrm{dl}$. Humanes Il- 6 wurde mit einem hochsensitiven Sandwich-ELISA nach dem Protokoll des Herstellers bestimmt (R\&D Systems, Abingdon, Großbritannien). Mit den Seren von 38 gesunden Erwachsenen wurden unabhängige Referenz-Intervalle für Il-6 im Serum festgelegt. Die Serumkonzentrationen von $S 100 \beta$ wurden mit einem zweiseitigen immunoluminometrischen Test nach den Vorgaben des Herstellers (LIA-Sangtech Medical, Bromma, Schweden) gemessen. MIA wurde mit einem „enzyme-linked immunosorbent assay“ (ELISA) nach dem Protokoll des Herstellers (Roche Diagnostics, Mannheim) gemessen.

\section{Statistische Methoden}

Für Il-6 wurden Grenzwerte mit der maximal-selektierten $\chi^{2}$-Statistik geschätzt [17]. Die Trennfähigkeit der Serumparameter (S100ß, MIA, LDH, CRP, Il-6) bez. einer dichotomen Zielgröße wurde mit der standardisierten Mann-Whitney(MW)-Statistik getestet. MW ist äquivalent zur Fläche unter der „Receiver Operating Characteristic“(ROC)-Kurve (,area under the ROC curve“, ROC-AUC), in der die Paare falsch positiver Testergebnisse (1-Spezifität) und richtig positiver Testergebnisse (Sensitivität) für die Realisierungen eines quantitativen Testes grafisch darstellt werden. Konfidenz-Intervalle der ROC-AUCs wurden unter Verwendung von Bootstrap-Stichproben errechnet [18]. Nichtparametrische Vergleiche der ROC-AUC wurden nach der Methode von DeLong [19] unter Verwendung der S-Funktionen von Hellmich [20] vorgenommen. Schätzwerte und Konfidenzintervalle für Sensitivitäten und Spezifitäten der Serumparameter wurden mit binären bzw. ordinalen logistischen RegressionsModellen berechnet, in denen eine der Kovariaten der Goldstandard ist [21,22].

Diagnostische Marker zur Erkennung von Metastasierungs-Progredienz wurden mit Hilfe eines multiplen logistischen Regressions-Modells mit der Metastasierungs-Progredienz als dichotomer Responsevariablen untersucht. Einflussvariable des Modells waren neben Alter und Geschlecht die $\log 10$-transformierten Werte der Serum-Marker (1. Studie: Il-6, CRP, LDH; 2. Studie: LDH, S100ß, MIA; 3. Studie: LDH, CRP, S100ß, MIA) als mögliche diagnostische Marker. Eine rückwärts gerichtete Selektions-Prozedur unter Verwendung des Informations-Kriteriums von Akaike (AIC) als Stopp-Regel wurde benutzt, um relevante Faktoren zu identifizieren [23]. Die Validierung des Modells erfolgte durch Verwendung von Bootstrap-Stichproben [23].

Paarweise Korrelationen zwischen zwei Markern wurden mit dem Korrelationskoeffizienten nach Spearman beschrieben. Approximative 95\%-Konfidenzgrenzen der Korrelationskoeffizienten wurden mit Hilfe der Z-Transformation nach Fisher errechnet. „Classification and regression trees“ (CART) [24,25] wurden alternativ zu logistischen Regressions-Modellen verwandt, um die besten Kombinationen der Serum-Marker zur Verlaufsbeobachtung des Therapieerfolges zu finden. 


\section{Il-6 und sein Surrogat CRP zum Monitoring des fernmetastasierten Melanoms geeignet}

In einer ersten Studie wurde getestet, ob sich Il-6 oder sein Surrogat CRP zur Verlaufsbeobachtung der fernmetastasierten Melanom-Erkrankung eignen. Um eine obere Normgrenze zu etablieren, wurde Il-6 im Serum von gesunden Freiwilligen bestimmt. Durch eine nicht-parametrische Berechnung wurde hierfür die notwendige Anzahl der gesunden Probanden mit 38 festgelegt, um das Kriterium zu erfüllen, dass mit einer Wahrscheinlichkeit von 0,9 mindestens 90\% der Population zwischen den Extremwerten der Stichprobe liegt [26]. Unter Verwendung dieser Prozedur zeigte sich ein maximaler Il-6-Wert in der Stichprobe von 3,2 ng/ml, so dass wir diesen Wert als oberen Grenzwert für Il-6 in den weiteren Analysen der Melanom-Patienten wählten.

74 Patienten mit einer Melanom-Erkrankung Stadium IV nach AJCC wurden in die Auswertung einbezogen. Die Staging-Ergebnisse ergaben für 37 Patienten eine Progredienz und für $37 \mathrm{~Pa}$ tienten eine Nicht-Progredienz der Fernmetastasierung. Beide Gruppen unterschieden sich in Geschlecht (Mann-Whitney-Test $\mathrm{p}=0,51$ ) und Alter (Fisher's-Exact-Test $\mathrm{p}=0,27$ ) nicht statis- tisch signifikant voneinander. Die Daten von Il-6, CRP und LDH bei einzelnen Patienten sind in Abb. 1 grafisch dargestellt. Wurden ihre Verteilungen durch Medianwerte und Quartile beschrieben, zeigten sich alle Marker bei Patienten mit Progression der Melanom-Erkrankung deutlich erhöht (Mann-Whitney-Test $\mathrm{p}<0,001$ für Il-6, CRP und LDH) [27].

Die Grenzwerte 3,2 pg/ml (Il-6), 0,5 mg/dl (CRP) und 240 U/1 (LDH) zugrundeliegend wurden die Sensitivitäten und Spezifitäten der Serum-Parameter bestimmt. Die Sensitivitäten von Il-6 $(0,86)$ und $\operatorname{CRP}(0,76)$ waren der $\operatorname{LDH}(0,73)$ überlegen. Hingegen zeigte die LDH die höchste Spezifität von 94\% (Il-6 0,78; CRP $0,88)$. Die gemeinsame Darstellung von Sensitivitäten und Spezifitäten in Bezug auf die Trennung von Progredienz von NichtProgredienz der Erkrankung erfolgte mit ROC-Kurven (Abb. 2). Die Flächen unter den ROC-Kurven waren für Il-6, CRP und LDH vergleichbar groß (Il-6 0,88; CRP 0,87; LDH 0,92).

\section{Konventionelle LDH den Melanom-Markern S100 $\beta$ und MIA nicht unterlegen}

In die zweite Studie wurden 71 Patienten mit Melanom-Erkrankung Stadium IV nach AJCC eingeschlossen. Die Staging-Untersuchungen ergaben für 34 Patienten eine Progression der Metastasierung und für 37 Patienten eine Nicht-Progression der Metas-
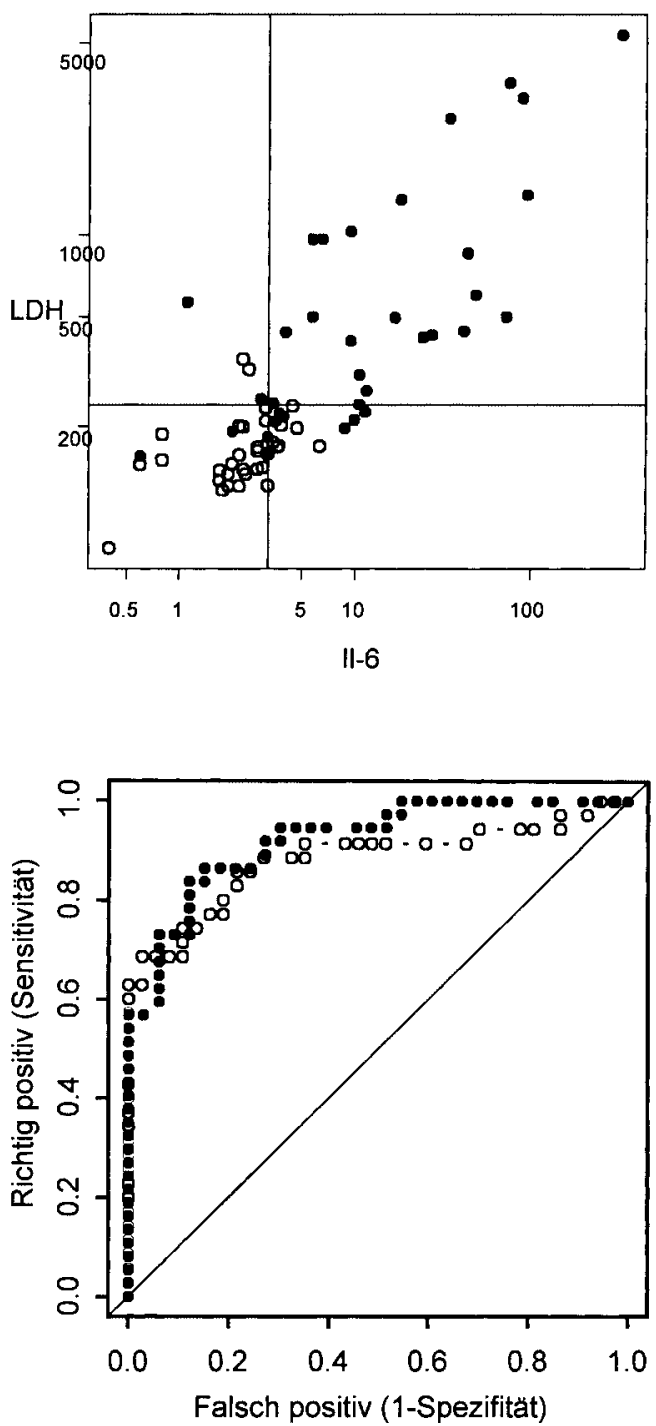
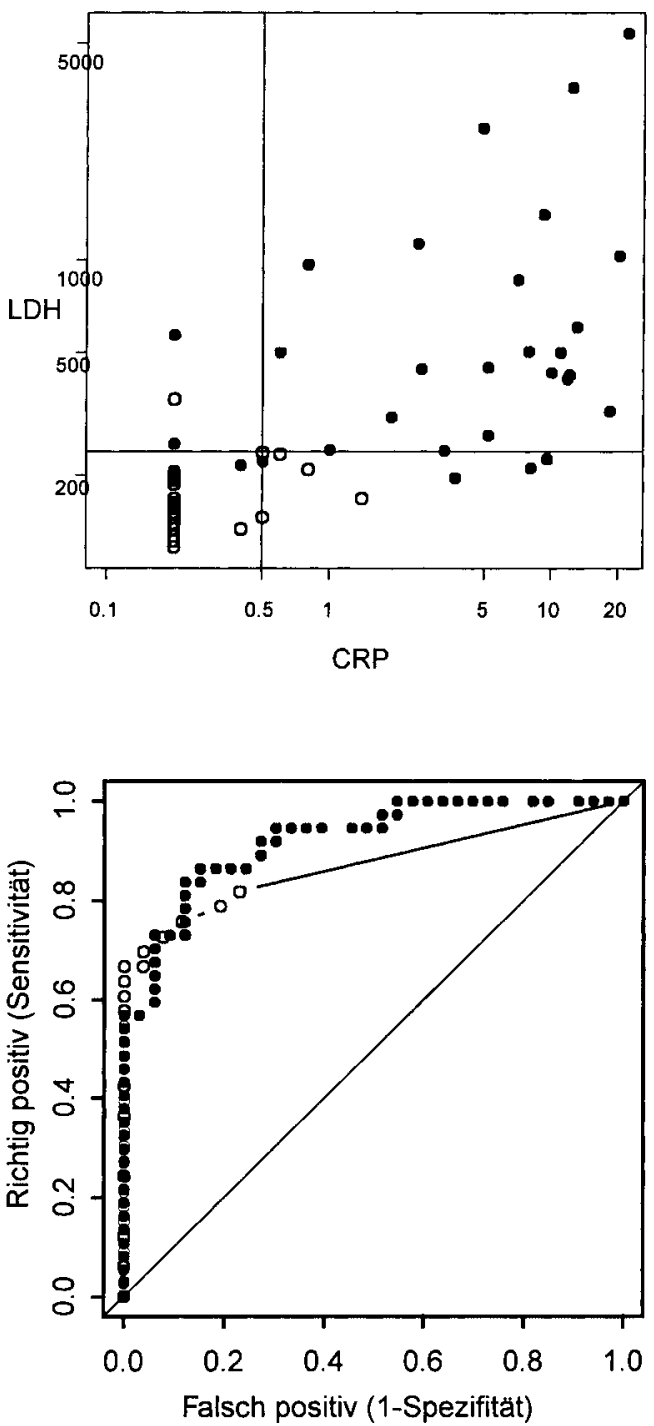

Abb. 1 Zweidimensionale Streudiagramme der Serum-Marker II-6 versus LDH (links) und CRP versus LDH (rechts) für MelanomPatienten mit Progredienz (Punkte) und Nicht-Progredienz der Fernmetastasierung (Kreise). Jeder Punkt und jeder Kreis repräsentiert jeweils einen Patienten.

Abb. 2 ROC-Kurven von LDH (Punkte) versus II-6 (Kreise, links) und versus CRP (Kreise, rechts). Jeder Punkt bzw. jeder Kreis repräsentiert jeweils einen Grenzwert der Serum-Marker. Die Flächen unter den ROC-Kurven sind vergleichbar groß. 


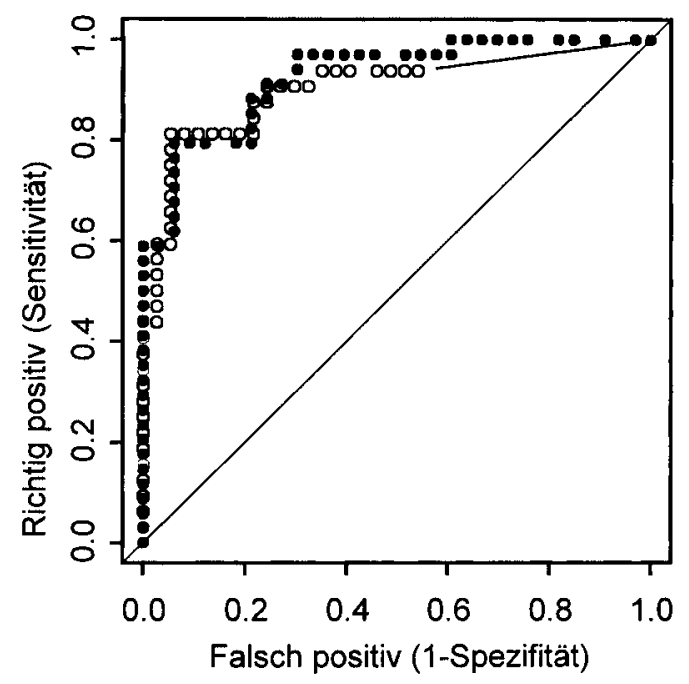

tasierung. Beide Gruppen unterschieden sich in Alter (MannWhitney-Test $\mathrm{p}=0,34$ ) und Geschlecht (Fisher's-Exact-Test $p=0,64)$ nicht statistisch signifikant voneinander. Zur besseren Vergleichbarkeit unserer Ergebnisse entschieden wir, bei der statistischen Auswertung die bereits publizierten Grenzwerte $0,12 \mu \mathrm{g} / \mathrm{l}(\mathrm{S} 100 \beta)$ und $6,50 \mathrm{ng} / \mathrm{ml}$ (MIA) zu verwenden. Wurden die Verteilungen durch Median-Werte und Quartile beschrieben, zeigten sich alle getesteten Serum-Marker bei Patienten mit Progression der Melanom-Metastasierung statistisch signifikant erhöht (Mann-Whitney-Test $\mathrm{p}<0,001$ für LDH, S100ß und MIA) [28].

In der Sensitivität waren S100 $(0,91)$ und MIA $(0,88)$ dem konventionellen Parameter LDH überlegen $(0,79)$. Hingegen erreichte die LDH die höchste Spezifität mit $92 \%$ (S100ß 0,76; MIA 0,73). Wurden Sensitivitäten und Spezifitäten der Parameter zusammen in ROC-Kurven dargestellt, zeigten sich für alle drei Parameter vergleichbar große Flächen unter den Kurven (Abb. 3; ROC-AUC LDH 0,92; S100ß 0,91; MIA 0,87).

Als Nächstes wurden signifikante Serum-Marker zur Erkennung von Erkrankungs-Progression mit dem logistischen RegressionsModell identifiziert. Nach Anwendung der rückwärts gerichteten Selektions-Prozedur unter Verwendung des Informations-Kriteriums von Akaike resultierte die LDH als relevanter Faktor. Die Validierung mit 100 Bootstrap-Stichproben ergab 50\% Selektionen von LDH und nur 12 bzw. 8\% Selektionen von S100 $\beta$ oder MIA. Die Tatsache, dass S100 $\beta$ und MIA die Information der LDH nur geringfügig verbessern konnten, resultierte möglicherweise aus ihren hohen Korrelationen mit der LDH: Die Korrelations-Koeffizienten nach Spearman betrugen 0,73 (näherungweises $95 \%$ Konfidenz-Intervall 0,59; 0,82) für S100 $\beta$ und LDH, 0,65 (0,48; $0,77)$ für MIA und LDH, $0,78(0,67 ; 0,86)$ für S100ß und MIA.

\section{Verlaufsmessungen der Marker nicht aussagekräftiger als Einfachmessungen zum Zeitpunkt des Re-Stagings}

In diese dritte Studie wurden 67 Patienten mit fernmetastasiertem Melanom eingeschlossen. Die Staging-Untersuchungen zeigten bei 42 Patienten eine Progredienz und bei 25 Patienten keine Progredienz der Erkrankung an. In beiden Gruppen differierten Geschlecht (Fisher's-Exact-Test $\mathrm{p}=0,44$ ) und Alter
(Mann-Whitney-Test $\mathrm{p}=0,12$ ) nicht statistisch signifikant. Wurden die Verteilungen der Parameter mit Median-Werten und 95\%-Quartilen beschrieben, zeigten sich alle getesteten SerumMarker bei Patienten mit Progredienz der Melanom-Erkrankung statistisch signifikant erhöht (Mann-Whitney-Test LDH und CRP $\mathrm{p}<0,001 ;$ S100 $\beta \mathrm{p}=0,001$, MIA $\mathrm{p}=0,005)$ [29].

Die ROC-AUC-Werte für Einfach-Messungen beim Re-Staging (LDH 75,0; CRP 81,7; S1003 75,2; MIA 72,3) waren nicht kleiner als die ROC-AUC-Werte für die Änderungen der Marker unter der Therapie vom Zeitpunkt des Stagings zum Zeitpunkt des ReStagings (LDH 74,1; CRP 71,4; S100 $\beta$ 71,7; MIA 74,0). Die Unterschiede zwischen den ROC-AUC von CRP und S100 $\beta$ erwiesen sich als nur marginal statistisch signifikant verschieden (geschätzter Unterschied der Flächen: 6,48\%; 95\%-Konfidenz-Intervall: $[-3,88 \%, 16,83 \%] ; p=0,11), \quad$ CRP versus MIA $(9,38 \%$; $[-2,44 \%, 21,2 \%] ; p=0,06)$ und CRP versus LDH $(6,62 \% ;[-4,18 \%$, $17,42 \%] ; p=0,11)[29]$.

Ergänzend analysierten wir die Kriterien zur Diagnose einer progredienten Erkrankung mit „classification and regression trees“ (CART). Da das Ziel der Serum-Diagnostik die Identifizierung der 25 Patienten mit nicht-progredienter Erkrankung aus der Gesamtheit aller 67 Patienten war, setzten wir den naiven Fehler von 25 falsch klassifizierten aus 67 Patienten als initialen Wert von $100 \%$ fest. Das CART-Modell schloss alle Parameter-Daten zu den Zeitpunkten von Staging und Re-Staging und zusätzlich die absoluten Änderungswerte zwischen beiden Zeitpunkten ein. Wurde eine Progredienz der Metastasierung mit der LDH $>240$ U/l zum Zeitpunkt des Re-Stagings in Kombination mit $\mathrm{S} 100 \beta \geq 0 \mu \mathrm{g} / \mathrm{l}$ oder Anstieg von MIA > $3 \mathrm{ng} / \mathrm{ml}$ unter der Therapie diagnostiziert, konnte der Fehler der Klassifikation von 100\% auf 67 bzw. 61 \% reduziert werden. Das beste Ergebnis wurde mit einem CRP > 0,5 mg/dl zum Zeitpunkt des Re-Stagings in Kombination mit einem Anstieg von MIA > $3 \mathrm{ng} / \mathrm{ml}$ unter der Therapie erreicht. Bei dieser Kombination konnte der urprüngliche Fehler auf 55\% reduziert werden. Erstaunlicherweise wurde eine vergleichbar gute Reduktion auf 59\% durch alleinige Verwendung von CRP-Messungen beim Re-Staging mit einem Grenzwert von $0,5 \mathrm{mg} / \mathrm{dl}$ erreicht. 
Il-6 und CRP bei unseren AJCC-Stadium-IV Melanom-Patienten

Melanom-Zellen exprimieren Il-6 $[6,7,10]$ und werden in vitro in ihrer Proliferation durch Il-6 stimuliert [4-6]. In vivo sind erhöhte Serum-Spiegel des Il-6 bei Patienten mit metastasiertem Melanom mit einem Versagen von Immunchemotherapien und mit kürzeren Überlebenszeiten assoziiert [1-3]. In Anbetracht dieser publizierten Fakten stellten wir die Hypothese auf, dass Il6-Serum-Werte generell den Schweregrad der fortgeschrittenen Melanom-Erkrankung reflektieren, und untersuchten diesen Marker auf seinen Wert für die Verlaufsbeobachtung der fernmetastasierten Erkrankung unter Therapie.

Tatsächlich fanden sich hohe Il-6-Serum-Werte mit einer Progression der Metastasierung statistisch signifikant assoziiert [27]. Woher die große Menge an Il-6 im Serum stammt, bleibt unklar. Die Tatsache, dass vorwiegend Patienten mit großer Tumorlast erhöhte Il-6-Serum-Werte aufwiesen und dass Melanom-Zellen Il-6 exprimieren können [6-8,10], könnte vermuten lassen, dass Il-6 aus den Tumorzellen stammt. Tatsächlich ist bekannt, dass der Verlust der Wachstums-Inhibition bei fortgeschrittenen Melanomen mit einer Il-6-Expression assoziiert ist [30]. Aber auch tumorspezifische Immuninteraktionen mit T-Zellen, Makrophagen oder Monozyten könnten für die erhöhten Il-6-Serum-Werte verantwortlich sein, da auch für diese Zellen die Expression dieses Zytokins bekannt ist. Weitere Quellen von Il-6 könnten Fibroblasten oder Endothelzellen sein [31], die von den Tumorzellen rekrutiert werden. Neben Tumor- und umgebenden Zellen war Il-6 auch viralen Ursprungs vermutet worden. Sicher ist, dass Il-6 bei Melanom-Patienten nicht vom Humanen Herpesvirus Typ 8 (HHV-8) stammt, dessen Genom das Gen eines Il-6-Analogons enthält. Genome des HHV-8 konnten in Melanomen jedenfalls nicht nachgewiesen werden [32,33].

Nicht nur die Quelle des Il-6 in den Patienten-Seren, sondern auch die Rolle dieses Zytokins in der Melanom-Erkrankung ist bis heute ungeklärt. Auf der einen Seite stimuliert Il-6 möglicherweise die Tumorzellen in ihrer Proliferation $[4,6-8,10]$. Tumorzell-assoziiertes Il-6 könnte auch das Tumorwachstum durch Anregung der Angiogenese begünstigen [34] oder durch Beeinträchtigung der Immunabwehr in der Erkennung oder Zerstörung von Tumorzellen [35]. Auf der anderen Seite werden dem Il-6 antitumorale Effektor-Mechanismen zugerechnet: Dieses Zytokin regt die Differenzierung von zytotoxischen Zellen an [5] und induziert die Expression des Il-2-Rezeptors [36] als auch von Il-2 in mitogenstimulierten T-Zellen [5,37]. Die Rolle von Il-6 in der Tumor-Abwehr wird jedoch bis heute kontrovers diskutiert, da hohe Il-6-Konzentrationen die T-Zell-Proliferation auch inhibieren können $[37,38]$.

Da auch erhöhte Serum-Werte von CRP mit dem Versagen von Immunchemotherapien und mit kürzeren Überlebenszeiten bei Patienten mit metastasiertem Melanom assoziiert sind [3], testeten wir auch CRP auf seinen Wert in der Verlaufsbeobachtung der fortgeschrittenen Melanom-Erkrankung. Tatsächlich eignet sich CRP als Indikator für eine Progression der Melanom-Metastasierung genauso gut wie Il-6 und kann daher als sein Surrogat verwandt werden [27]. Da die Synthese von CRP in den Leberzellen hauptsächlich durch Il-6 induziert wird [11,12], scheint CRP die Sekretion von Il-6 zu reflektieren. Diese Beobachtung wird durch die hohe Korrelation zwischen den Serum-Werten von untermauert (Korrelationskoeffizient nach Spearman $\mathrm{p}=0,83$ ). Eine gesteigerte Synthese von CRP ist als Akut-Phase-Antwort jedoch ein unspezifisches Phänomen, das durch fast alle Formen von Gewebeschäden und Entzündung induziert wird [39].

Als Serum-Marker erwiesen sich Il-6 und CRP der konventionellen LDH ebenbürtig, die bereits früher als die beste prognostische Variable bezüglich des Überlebens des metastasierten Melanoms beschrieben wurde [13-15]. Für eine Reihe anderer Tumoren, z. B. kleinzellige und nicht-kleinzellige Bronchialkarzinome, Hodgkin- und Non-Hodgkin-Lymphome oder Prostatakarzinome, ist der prognostische Wert der LDH beschrieben [15]. Eine erhöhte Serum-LDH muss nicht notwendigerweise eine LeberMetastasierung anzeigen, wie früher vermutet wurde. Da die LDH relativ konstant metabolisiert wird, repräsentieren erhöhte Spiegel vielmehr den Tumorzell-Umsatz und die Tumorlast. In unserer zweiten Studie zeigten 43 \% der Patienten erhöhte LDHWerte im Serum, aber nur $21 \%$ hatten eine radiologisch nachweisbare Leber-Metastasierung. In dieser Studie verglichen wir die LDH mit S100 $\beta$ und dem MIA-Protein, die in Melanom-Zellen exprimiert werden und in Seren von Melanom-Patienten nachweisbar sind [40-43]. Für S100 $\beta$ ist bei Patienten mit Melanom ein prognostischer Wert belegt $[44,45]$. Bei metastasierter Erkrankung wurden S100 $\beta[41,43,46]$ als auch MIA $[40,42]$ im Serum gefunden, und bei einzelnen Patienten korrelierten Änderungen der Serum-Spiegel mit einem Ansprechen bzw. NichtAnsprechen der Therapie $[40,41,43]$.

Tatsächlich korrelierten erhöhte Serumwerte von S100 $\beta$ und MIA auch in unseren Analysen statistisch hoch signifikant mit dem Vorhandensein einer aktuellen Erkrankungs-Progression [28]. Unerwarteterweise waren S100 $\beta$ und MIA jedoch dem konventionellen Marker LDH in der logistischen Regressions-Analyse nicht überlegen. Weder S100 $\beta$ noch MIA erhöhten die Aussagekraft der konventionellen LDH. Was die Spezifität der LDH betrifft, kann dieser Parameter infolge einer Reihe von Gewebeschäden erhöht sein, z. B. durch Hepatitis, Hämolyse oder Myokardinfarkt. Unspezifische Erhöhungen sind jedoch auch bei S100 $\beta$ und MIA möglich: Neben Melanom-Zellen werden diese beiden Proteine auch in Chondrozyten exprimiert [47]. Wird S100 $\beta$ bei Patienten mit zerebralen Malignomen oder nach apoplektischen Insulten bestimmt, finden sich Erhöhungen im Serum bei 90 bzw. 40\% der Patienten [48]. Auch MIA fand sich bei bis zu 17\% der Patienten mit epithelialen Neoplasien im Serum erhöht [40] und wird sogar als Marker der destruierenden Rheumatoiden Arthritis diskutiert [49]. Es handelt sich daher auch bei S100 $\beta$ und MIA nicht um hochspezifische Melanom-Marker.

Die dritte Studie initiierten wir zur Evaluierung der Änderungen von LDH, S100 $\beta$ und MIA unter Therapie als Kriterien, Progression von Nicht-Progression der Erkrankung zu unterscheiden. Tatsächlich fanden sich Abnahmen von LDH, S100 $\beta$ und MIA unter Therapie mit einem Ansprechen der Therapie des fernmetastasierten Melanoms assoziiert, wogegen Anstiege der Parameter eine Progredienz der Metastasierung anzeigten. Jedoch war in den ROCAnalysen der individuelle diagnostische Wert der Marker-Änderungen nicht dem diagnostischen Wert der Einfach-Messwerte überlegen. Daher sind Änderungen von LDH, S100 $\beta$ und MIA unter der Therapie nicht besser als Einfach-Messungen zum Zeitpunkt des Re-Stagings zur Verlaufskontrolle geeignet [29]. 
Ähnlich der LDH erreichte das CRP als Serum-Marker in dieser dritten Studie eine Sensitivität und Spezifität, die den Ergebnissen von S100ß and MIA vergleichbar gut war. Dieses Ergebnis fand sich sowohl für Änderungen der Parameter unter Therapie als auch für Einfach-Messungen zum Zeitpunkt des Re-Stagings. Unter Anwendung der CART-Analyse erwies sich das CRP mit einem Grenzwert von $0,5 \mathrm{mg} / \mathrm{dl}$ sogar als der am meisten relevante Parameter [29]. Keine Kombination der Serum-Marker ergab ein besseres individuelles diagnostisches Ergebnis als das CRP zum Zeitpunkt des Re-Stagings alleine. Trotzdem ist zu fragen, ob die Einfach-Messwerte von CRP mit einer geschätzten ROC-AUC von 81,67\% ein zufriedenstellendes Ergebnis liefert, da die geschätzte Sensitivität unter $80 \%$ bei einer geschätzten Spezifität von mindestens $70 \%$ liegt. Wird die Spezifität auf $90 \%$ fixiert, fällt die Sensitivität auf $60 \%$.

Zusammenfassend sind neben S100 $\beta$ und MIA auch die konventionelle LDH, das Zytokin Il-6 und sein Surrogat CRP als Indikatoren für eine Progredienz der fernmetastasierten Melanom-Erkrankung geeignet. Da CRP im Serum die Il-6-Spiegel reflektiert und beide Marker eng korrelieren, ist die Bestimmung von CRP als schneller und preiswerter Test zu empfehlen.

\section{Danksagung}

Der Autor dankt Herrn Axel Benner vom Deutschen Krebsforschungszentrum herzlich für die enge Kooperation.

\section{Literatur}

${ }^{1}$ Mouawad R, Benhammouda A, Rixe O, Antoine EC, Borel C, Weil M, Khayat D, Soubrane C. Endogenous interleukin 6 levels in patients with metastatic malignant melanoma, correlation with tumor burden. Clin Cancer Res 1996; 2: 1405-1409

2 Tartour E, Dorval T, Mosseri V, Deneux L, Mathiot C, Brailly H, Montero F, Joyeux I, Pouillart P, Fridman WH. Serum interleukin 6 and C-reactive protein levels correlate with resistance to Il-2 therapy and poor survival in melanoma patients. Br J Cancer 1994; 69: 911 -913

${ }^{3}$ Tartour E, Blay JY, Dorval T, Escudier B, Mosseri V, Douillard JY, Deneux L, Gorin I, Negrier S, Mathiot C, Pouillart P, Fridman WH. Predictors of clinical response to interleukin-2-based immunotherapy in melanoma patients, a French multiinstitutional study. J Clin Oncol 1996; 14: $1697-1703$

${ }^{4}$ Candi E, Knight RA, Spinedi A, Guerrieri P, Melino G. A possible growth factor role of Il-6 in neuroectodermal tumors. J Neurooncol 1997; 31: $115-122$

${ }^{5}$ Kishimoto T, Akira S. Interleukin-6 and its receptor, a paradigm for cytokines. Science 1992; 258: $593-597$

${ }^{6}$ Lee JD, Sievers TM, Skotzko M, Chandler CF, Morton DL, McBride WH, Economou JS. Interleukin-6 production by human melanoma cell lines. Lymphokine Cytokine Res 1992; 11: 161 - 166

${ }^{7}$ Francis GM, Krohn EG, Woods KV, Buzaid AC, Grimm EA. Interleukin-6 production and secretion in human melanoma cell lines, regulation by interleukin-1. Melanoma Res 1996; 6: 191 - 201

${ }^{8}$ Lu C, Kerbel RS. Interleukin-6 undergoes transition from paracrine growth inhibitor to autocrine stimulator during human melanoma progression. J Cell Biol 1993; 120: 1281 - 1288

${ }^{9}$ Mattei S, Colombo MP, Melani C, Silvani A, Parmiani G, Herlyn M. Expression of cytokine/growth factors and their receptors in human melanoma and melanocytes. Int J Cancer 1994; 56: 853 - 857

${ }^{10}$ Colombo MP, Maccalli C, Mattei S, Melani C, Radrizzani M, Parmiani G. Expression of cytokine genes, including Il-6, in human malignant melanoma cell lines. Melanoma Res 1992; 2: 181-189

${ }^{11}$ Castell JV, Gomez-Lechon MJ, David M, Andus T, Geiger T, Trullenque R, Fabra R, Heinrich PC. Interleukin-6 is the major regulator of acute phase protein synthesis in adult human hepatocytes. FEBS Lett 1989; 242: $237-239$

${ }^{12}$ Moshage HJ, Roelofs HMJ, van Pelt JF, Hazenberg BPC, van Leeuwen MA, Limburg PC, Aarden LA, Yap SH. The effect of interleukin-1, interleukin- 6 and its interrelationship on the synthesis of serum amyloid $A$ and C-reactive protein in primary cultures of adult human hepatocytes. Biochem Biophys Res Commun 1988; 155: $112-117$

${ }^{13}$ Heimdal K, Hannisdal E, Gunderson S. Metastatic malignant melanoma. Eur J Cancer 1989; 25: 1219-1223

${ }^{14}$ Keilholz U, Scheibenbogen C, Sommer M, Pritsch M, Geuke AM. Prognostic factors for response and survival in patients with metastatic melanoma receiving immunotherapy. Melanoma Res 1996; 6: $173-178$

${ }^{15}$ Sirott MN, Bajorin DF, Wong GYN, Tao Y, Chapman PB. Prognostic factors in patients with metastatic malignant melanoma. Cancer 1993; 72: 3091 - 3098

${ }^{16}$ Balch CM, Buzaid AC, Atkins MB, Cascinelli N, Coit DG, Fleming ID, Houghton A, Kirkwood JM, Mihm MF, Morton DL, Reintgen D, Ross MI, Sober A, Soong SJ, Thompson JA, Thompson JF, Gerhenwald JE, McMasters KM. A new American joint committee on cancer staging system for cutaneous melanoma. Cancer 2000; 88: 1484-1491

${ }^{17}$ Miller R, Siegmund D. Maximally selected chi square statistics. Biometrics 1982; 38: 1011 - 1016

${ }^{18}$ Efron B, Tibshirani RJ. An Introduction to the Bootstrap. New York: Chapman \& Hall, 1993

${ }^{19}$ DeLong ER, DeLong DM, Clarke-Pearson DL. Comparing the areas under two or more correlated receiver operating characteristic curves, a nonparametric approach. Biometrics 1988; 44: 837-845

${ }^{20}$ Hellmich M. Receiver Operating Characteristic (ROC) Kurven und Flächen darunter. Anwendungen in der Psychiatrie. Dissertationsschrift. Med. Fakultät, Universität Münster, 1996

${ }^{21}$ Coughlin SS, Trock B, Criqui MH, Pickle L, Browner D, Tefft MC. The logistic modelling of sensitivity, specificity and predictive value of a diagnostic test. J Clin Epidemiol 1992; 45: 1 - 7

22 Smith PJ, Thompson TJ, Engelgau M, Herman WH. A generalized linear model for analysing receiver operating characteristic curves. Statistics in Medicine 1996; 15: 323-333

${ }^{23}$ Harrell FE. Predicting outcomes, applied survival analysis and logistic regression. University of Virginia, 2001

${ }^{24}$ Breiman L, Friedman JH, Olshen RA, Stone CJ. Classification and Regression Trees. Belmont, CA: Wadsworth Inc, 1984

${ }^{25}$ Lausen B, Sauerbrei W, Schumacher M. Classification and regression trees (CART) used for the exploration of prognostic factors measured on different scales. In: Dirschedl P, Ostermann R (Eds). Computational Statistics. Heidelberg: Physica Verlag, 1994: 483-496

${ }^{26}$ Harman AJ. Wilks' tolerance limit sample size. In: Sachs L (Ed). Angewandte Statistik. Heidelberg: Springer Verlag, 1997: 215 - 218

${ }^{27}$ Deichmann M, Benner A, Jäckel A, Bock M, Waldmann V, Näher $\mathrm{H}$. Elevated interleukin-6 serum levels indicate progressive disease in metastasized malignant melanoma. J Exp Clin Cancer Res 2000; 19: $301-307$

${ }^{28}$ Deichmann M, Benner A, Bock M, Jäckel A, Waldmann V, Uhl K, Näher H. S100-beta, melanoma-inhibiting activity, and lactate dehydrogenase discriminate progressive from nonprogressive American Joint Committee on Cancer stage IV melanoma. J Clin Oncol 1999; 17: $1891-1896$

${ }^{29}$ Deichmann M, Benner A, Kuner N, Wacker J, Waldmann V, Näher $\mathrm{H}$. Are responses to therapy of metastasized malignant melanoma reflected by decreasing serum values of $S 100 \beta$ or melanoma inhibitory activity (MIA)? Melanoma Res 2001; 11: $291-296$

30 Paglia D, Oran A, Lu C, Kerbel RS, Sauder DN, McKenzie RC. Expression of leukemia inhibitory factor and interleukin-11 by human melanoma cell lines, LIF, Il-6 and Il-11 are not coregulated. J Interferon Cytokine Res 1995; 15: $455-460$

${ }^{31}$ Klein B, Zhang XG, Jourdan B, Content B, Content J, Houssiau F, Aarden L, Piechaczyk M, Bataille R. Paracrine rather than autocrine regulation of myeloma-cell growth and differentiation by interleukin-6. Blood 1989; 73: $517-526$

32 Deichmann M, Thome M, Bock M, Jäckel A, Waldmann V, Näher H. The human herpesvirus-type 8 DNA is not detected in primary malignant melanoma. Br J Cancer 1999; 80: 67-69

${ }^{33}$ Helmke BM, Deichmann M, Otto HF. Anorectal melanomas do not harbour the Kaposi's sarcoma associated human herpesvirus type 8 DNA. J Med Virol 2001; 64: 47-50 
${ }^{34}$ Motro B, Itin A, Sachs L, Keshet E. Patterns of interleukin-6 gene expression in vivo suggests a role for this cytokine in angiogenesis. Proc Natl Acad Sci USA 1990; 87: 3092 - 3096

${ }^{35}$ Okuno Y, Takahashi T, Suzuki A, Fukumoto M, Nakamura K, Fukui H, Koishihira Y, Ohsugi Y, Imura H. Acquisition of growth autonomy and tumorigenicity by an interleukin 6-dependent human myeloma cell line transfected with interleukin 6 cDNA. Exp Hematol 1992; 20: $395-400$

${ }^{36}$ Noma T, Mizuta T, Rosen A, Hirano T, Kishimoto T, Honjo T. Enhancement of the interleukin 2 receptor expression on T cells by multiple B-lymphotropic lymphokines. Immunol Lett 1987; 15: 249-253

${ }^{37}$ Aderka D, Le J, Velcek J. Il-6 inhibits lipopolysaccharide-induced tumour necrosis factor production in cultured human monocytes, U937 cells, and in mice. J Immunol 1989; 143: 3517 - 3524

38 Zhou D, Munster A, Winchurch RA. Pathologic concentrations of interleukin 6 inhibit T cell responses via induction of activation of TGF- $\beta$. FASEB J 1991; 5: $2582-2585$

${ }^{39}$ Pepys MB. The acute phase response and C-reactive protein. In: Weatherall DJ, Ledingham JGG, Warrell DA (Eds). Oxford textbook of medicine. Oxford: Oxford University Press, 1995: 1527-1533

${ }^{40}$ Bosserhoff AK, Kaufmann M, Kaluza B, Bartke I, Zirngibl H, Hein R, Stolz W, Buettner R. Melanoma-inhibiting activity, a novel serum marker for progression of malignant melanoma. Cancer Res 1997; 57: $3149-3153$

${ }^{41}$ Guo HB, Stoffel-Wagner B, Bierwirth T, Mezger J, Klingmüller D. Clinical significance of serum S100 in metastatic malignant melanoma. Eur J Cancer 1995; 31: 924-928
${ }^{42}$ Hein R, Bosserhof AK, Stolz W, Kaufmann M, Kaluza B, Buettner R. MIA serum levels as a detection and monitoring system of malignant melanoma. Arch Dermatol Res 1997; 289: 30

${ }^{43}$ Henze G, Dummer R, Joller-Jemelka HI, Böni R, Burg G. Serum S100, a marker for disease monitoring in metastatic melanoma. Dermatology 1997; 194: 208-212

${ }^{44}$ Hauschild A, Michaelsen J, Brenner W, Rudolph P, Glaser R, Henze E, Christophers E. Prognostic significance of serum $S 100 \beta$ detection compared with routine blood parameters in advanced metastatic melanoma patients. Melanoma Res 1999; 9: 155-161

${ }^{45}$ Hauschild A, Engel G, Brenner W, Glaser R, Monig H, Henze E, Christophers E. S100 $\beta$ protein detection is a significant prognostic factor in metastatic melanoma. Oncology 1999; 56: 338-344

46 Jäckel A, Deichmann M, Waldmann V, Bock M, Näher H. S100ß protein in serum, a tumor marker in malignant melanoma, current state of knowledge and clinical experience. Hautarzt 1998; 50: 250-256

${ }^{47}$ Dietz U, Sandell LJ. Cloning of a retinoid acid-sensitive mRNA expressed in cartilage and during chondrogenesis. J Biol Chem 1996; 271: $3311-3316$

48 Fagnart OC, Sindic CJM, Laterre C. Particle counting immunoassay of S100 protein in serum, possible relevance in tumors and ischemic disorders of the central nervous system. Clin Chem 1988; 34: 1387-1391

${ }^{49}$ Müller-Ladner U, Bosserhoff AK, Dreher K, Hein R, Neidhart M, Gay S, Scholmerich J, Buettner R, Lang B. MIA (melanoma inhibitory activity), a potential serum marker for rheumatoid arthritis. Rheumatology 1999; 38: $148-154$ 